\title{
CONTRIBUIÇÕES DE UMA TRILHA ECOLÓGICA PARA AS PERCEPÇÕES DE MEIO AMBIENTE DOS ESTUDANTES
}

\section{MARCELO BORGES ROCHA.}

Centro Federal de Educação Tecnológica Celso Suckow da Fonseca - CEFET/RJ

E-mail: rochamarcelo36@yahoo.com.br

\section{José RenATO de Oliveira Pin.}

Centro Federal de Educação Tecnológica Celso Suckow da Fonseca - CEFET/RJ

E-mail: jrtpin@hotmail.com

\section{YASMIN CUNHA BULHÕES GÓES.}

Centro Federal de Educação Tecnológica Celso Suckow da Fonseca - CEFET/RJ

E-mail: yasmin-goes@hotmail.com

\section{LAURA ALVES RODRIGUES.}

Centro Federal de Educação Tecnológica Celso Suckow da Fonseca - CEFET/RJ

E-mail: laura.rodrigues94@hotmail.com

\section{RESUMO OU RESUMEN:}

Os estudos de como os indivíduos sentem, agem e pensam, no âmbito da paisagem vivida, pode colaborar com a proposição de medidas que visem à qualidade ambiental e à integração das pessoas com o meio. Sendo assim, este estudo tem como objetivo investigar as percepções sobre meio ambiente de estudantes do ensino superior durante a realização de uma trilha ecológica no Parque Nacional da Tijuca, Rio de Janeiro. Para tal, foram realizadas entrevistas com os alunos antes e após a trilha. Como resultado constatou-se que ocorreram alterações significativas nas compreensões dos estudantes após a realização da trilha, com destaque no que diz respeito aos impactos causados ao meio ambiente e suas consequências para o planeta.

\section{PALAVRAS-CHAVE:}

meio ambiente, trilha ecológica, percepção ambiental.

\section{CONTRIBUTIONS OF AN ECOLOGICAL TRACK IN THE ENVIRONMENTAL PERCEPTIONS OF STUDENTS}

\section{ABSTRACT:}

The studies about how individuals feel, act and think, within the context of the lived landscape, can collaborate with the proposal of measures that aim at environmental quality and the integration of people with the environment. Thus, this study aims to investigate the perceptions about the environment of students of higher education during the realization of an ecological trail in the 
Parque Nacional da Tijuca, Rio de Janeiro. To this end, interviews were conducted with the students before and after the trail. As a result, it was found that there were significant changes in the students' comprehension after the trail was done, with emphasis on the impacts caused to the environment and its consequences for the planet.

\section{KEYWORDS:}

Environment, ecological trail, environmental awareness.

\section{INTRODUÇÃO}

No contexto de uma educação para a vida em sociedade, pautada em princípios que apropriem o indivíduo de uma autonomia crítica, não fechada em si, a educação consolida-se, no século XXI, como proposta de formação do ser humano da perspectiva axiológica pautada em contextos dialógicos e multidimensionais. Nesse propósito, conforme discorrem Parreira e José Filho (2011) o processo formativo do educando, utilizando-se de espaços não formais, pode ser favorecido pela construção individual e coletiva de atitudes, conceitos e procedimentos que formarão indivíduos mais críticos e conscientes.

Nesse sentido, Teramussi (2008) afirma que a percepção ambiental deve ser considerada imprescindível quando vista como a principal forma de interação com o meio ambiente e qualidade/mitigação ambiental. A tomada de consciência da importância e influência do meio ambiente para com a sociedade e o planeta passa a ser notável quando um indivíduo, instigado por alguma atividade ou pensamento, ao sensibilizar-se, percebe o ambiente com um novo olhar.

Para Teramussi (op. cit.), o homem tende a ter em seu interior percepções já formadas que têm como base, situações por ele vivenciadas, experiências e interpretações que o fizeram compartilhar determinadas opiniões. Nesse sentido, as trilhas ecológicas, como espaços naturais abertos, como laboratórios propícios a sensações, configuram-se como locais que aguçam as percepções dos visitantes, com grande potencial reflexivo e capaz de revelar novas interpretações. São as 


\section{DEDebates

relevâncias interpretativas reveladas pelo pensamento reflexivo/interpretativo que subsidiam uma possibilidade na mudança de opinião, na mudança de concepções.

De acordo com Teramussi (2008, p.15):

Percepção é o entendimento, a mediação entre o sujeito e o que está exterior a ele, ou seja, entre as pessoas e o meio em que se inserem. A paisagem pode ser compreendida justamente como fruto da percepção, da relação entre a subjetividade e a objetividade. A percepção é o instrumento do uso do espaço.

Sendo assim, Costa et al. (2014) destacam que o contato direto com os conteúdos ecológicos presentes nas trilhas e a análise pessoal dos elementos da natureza, despertam nos estudantes, a curiosidade e o interesse de aprender, já que os mesmos estão participando de uma metodologia de ensino, que empiricamente gera o desenvolvimento de novas compreensões acerca do meio ambiente. Nesse contexto é possível entender que as trilhas ecológicas têm um grande potencial motivacional e atrativo à reelaboração de percepções ambientais, pois para aqueles que as visitam representa a fuga do cotidiano e a realidade dos conteúdos estudados em sala de aula, levando-os a uma nova interpretação.

Ainda para esses autores, as trilhas têm a potencialidade de fazer com que os estudantes percebam-se como parte integrante e não apenas meros expectadores de inter-relações entre homem-ambiente. Além disso, a reflexão sobre as relações entre o ser humano e o meio ambiente, intensificada pelo conjunto sensível (elementos materiais e não materiais) das trilhas ecológicas, torna o processo de formação de uma nova concepção mais simples.

Ademais, Costa et al. (2014) observam que a utilização de trilhas favorecem a estudantes, ganhos relativos às dimensões sociais e afetivas, proporcionando uma 


\section{DEDebates

melhoria na autoestima, no senso de responsabilidade pessoal e coletiva, no que concerne a construção da cidadania e percepção ambiental.

Gonçalves (2009) corrobora o discurso do uso de trilhas ecológicas para a formação cidadã, em especial do viés da Educação Ambiental, ao salientar que esses espaços naturais constituem-se em uma grande ferramenta para o desenvolvimento dos conteúdos relacionados ao meio ambiente. Para a autora, as trilhas facilitam a interação com a natureza e a inclusão do homem nos ambientes que o cercam, bem como podem alertar e educar o visitante quanto às questões ambientais voltadas a saúde e ao equilíbrio ambiental. É visível que as trilhas permitem o estudante sentirse parte do meio, logo, desempenham também um papel importante como corpus de um processo de mudança nas percepções ambientais desses estudantes.

Conforme Gonçalves (2009, p.9):

Por meio das trilhas podemos abordar não só elementos ecológicos e naturais do meio ambiente como também podemos incluir nessa situação elementos culturais, éticos, lúdicos e sociais e de percepção ambiental.

Diante disto, percebe-se que o valor dado às trilhas se justifica pelo seu potencial em consolidar e descobrir novos conhecimentos. As trilhas configuram-se como locais para questionamentos que irão despertar uma busca por novas perspectivas, sendo assim, temos a possibilidade de trabalhar a percepção, a curiosidade e a interação homem/natureza. Visto o importante papel desempenhando pelas trilhas ecológicas, este estudo investiga as contribuições de uma trilha no Parque Nacional da Tijuca no Rio de Janeiro para as percepções que estudantes do ensino superior possuem sobre meio ambiente. 


\section{DEDebates \\ em Educação Científica e Tecnológica

\subsection{CONTRIBUIÇÕES DAS TRILHAS ECOLÓGICAS PARA OS PROCESSOS DE INTERPRETAÇÃO AMBIENTAL}

A principal função das trilhas sempre foi a de suprir a necessidade de deslocamento. No entanto, segundo Mitraud (2003), ao longo dos anos, houve uma alteração de valores em relação às trilhas. Atualmente, as trilhas ecológicas oferecem aos visitantes a oportunidade de desfrutar de uma área de maneira harmônica e alcançar maior familiaridade com o meio natural. Trilhas bem construídas e devidamente mantidas protegem o ambiente do impacto do uso e ainda asseguram aos trilheiros maior conforto, segurança e satisfação. Esses cuidados terão papel significativo na impressão que o visitante levará sobre a área e a instituição que a gerencia.

Com o desenvolvimento adequado de trilhas e o aumento da consciência de que trilhas em Unidades de Conservação (UC) ou em outras áreas onde se pratica ecoturismo e educação ambiental, não são picadas improvisadas, espera-se que, não só novas áreas sejam abertas de forma correta (com mitigação de impacto ambiental), mas que também possam servir de recurso para desenvolvimento de projetos educativos, que contribuam para a tomada de uma consciência ambiental não antropocêntrica.

Dentro do trabalho de trilhas ecológicas, segundo Vasconcellos (1998), o desenvolvimento da interpretação ambiental (IA) está ligado à história e visitação nos parques norte-americanos, onde os chamados "naturalistas" acompanhavam grupos de pessoas por trilhas, descrevendo os aspectos naturais do ambiente, fazendo com que as pessoas se interessassem pelas questões ambientais.

Para Oliveira e Nishida (2011) a IA foi desenvolvida sem uma sistematização durante décadas, suas bases conceituais e filosóficas só foram estabelecidas em 1957 por Freeman Tilden que define a interpretação ambiental como "uma atividade educativa, que se propõe revelar significados e inter-relações por meio de uso de 
objetos originais, do contato direto com o recurso e de meios ilustrativos, em vez de simplesmente comunicar a informação literal" (TILDEN, 1957 apud OLIVEIRA E NISHIDA, 2011, p. 169).

Para Vasconcellos (1998), a interpretação ambiental é uma tradução da linguagem da natureza para linguagem comum dos visitantes, possibilitando informação em vez da distração e educação, além do divertimento. Neste sentido, as trilhas ecológicas são reconhecidas como mais um recurso para o desenvolvimento dos programas de ensino e educação ambiental nas áreas protegidas. No transcurso de uma trilha o caráter provocativo é evidenciado através de estímulos que tentam despertar a curiosidade e reflexões a partir da experiência real.

Dentre as potencialidades educativas das trilhas ecológicas, a (re)leitura do ambiente a qual elas estão inseridas tem papel considerável. Nesse sentido, Vasconcellos (1998) destaca que as trilhas têm caráter interpretativo quando seus recursos são traduzidos para o visitante através de guias especializados (intérpretes), de folhetos interpretativos, e de painéis ou ainda, através de gravações. Independentemente do método utilizado sempre se busca desenvolver nos visitantes um novo campo de percepções. Uma trilha de viés interpretativo é um meio e não um fim. E por isso, se a tomarmos como um recurso pedagógico deve ser planejada de acordo com os objetivos do programa interpretativo, as características e valores intrínsecos que o local oferece.

Tecendo uma reflexão sobre a qualidade das experiências ambientais vivenciadas durante a realização de atividades educativas em trilhas ecológicas, incluindo tanto as interpretativas quanto as vivências na natureza, podemos considerar que, ao enfatizar as formas de perceber e interpretar as paisagens do nosso entorno, constituímos aprendizados experienciais na busca de significados, propósitos e valores pró-ecológicos, econômicos e não tangíveis, que se refletem na 


\section{DEDebates

estruturação de mundos exteriores e interiores. Trata-se, portanto, de transpor as fronteiras tradicionais do modo de transmitirmos conhecimentos, utilizando-se do ambiente natural pouco antropizado, permitindo a ampliação de horizontes, de saberes, de possibilidades de intercâmbios, redes, partilhas e aprendizados vivenciais.

Esses espaços, em especial, as trilhas ecológicas vêm ao encontro do preconizado por Jacobi et al. (2004), pois constituem espaços naturais com possibilidades de práticas educativas, em especial, de caráter interdisciplinar, necessitando, para isso, que o professor identifique as potencialidades pedagógicas neles existentes, busque adequar metodologias, e perceba o modo como esses locais contribuem para a construção do conhecimento.

Trilla (2008) destaca que no contexto de uma educação para a vida em sociedade, pautada em princípios que apropriem o indivíduo de uma autonomia crítica, a educação consolida-se, no século XXI, como proposta de formação do ser humano em sua multidimensionalidade cultural, corporal e cognitiva. Nesse princípio, o processo formativo do educando, utilizando-se de espaços não formais, pode ser favorecido pela construção individual e coletiva de atitudes, conceitos e procedimentos que produzirão indivíduos mais críticos e conscientes.

Os espaços não formais pressupõem ao defendido por Faggionato (2014), para quem a compreensão das inter-relações entre o homem e o ambiente, suas expectativas, anseios, satisfações e insatisfações, julgamentos e condutas, pode ser, a cerro modo, alcançada pela percepção ambiental. Essa percepção pode ser compreendida como uma tomada de consciência do ambiente pelo homem, ou seja, o ato de perceber o ambiente que se está inserido, aprendendo a proteger e a cuidar do mesmo. Cada indivíduo percebe, reage e responde diferentemente às ações sobre o ambiente em que vive. As respostas ou manifestações daí decorrentes, às 
vezes tomadas de forma inconsciente, são resultado das percepções (individuais e coletivas), dos processos cognitivos, julgamentos e expectativas de cada pessoa.

Para Faggionato (2014) as ações de perceber e interpretar o ambiente podem ser utilizadas de forma a determinar as necessidades de uma população e propor melhorias com embasamento e entendimento dos problemas, alcançando mais eficiência na solução dos mesmos.

Nesse sentido, Marques (2001) acrescenta que educação científica e interpretação ambiental despontam como estruturas de defesa do meio natural, e ajudam a reaproximar o homem da natureza, garantindo um futuro com mais qualidade de vida para todos, já que despertam maior responsabilidade e respeito dos indivíduos para com o ambiente em que vivem.

\subsection{TIPOLOGIAS SOBRE MEIO AMBIENTE: APLICAÇÕES DE LUCIE SAUVÉ}

O conceito de meio ambiente junto à educação influencia e determina as escolhas que serão feitas pelo homem. Sensibilizar o indivíduo mostrando-o visões diferenciadas de meio ambiente, educação e desenvolvimento sustentável oferece subsídios para uma construção autônoma e significativa de conceitos que refletirão em comportamentos individuais e coletivos, que, por conseguinte contribuirão com o ambiente.

Sauvé (1996) apresenta ferramentas teóricas que podem ser usadas para uma análise crítica das correntes filosóficas que abarcam o desenvolvimento sustentável como objetivo final da relação do homem com o ambiente. Por meio de um estudo fenomenográfico de discursos e práticas em Educação Ambiental, a autora identificou seis conceitos paradigmáticos acerca do meio ambiente. O quadro 01 apresenta as tipologias de Meio Ambiente segundo Sauvé (1996). 
Quadro 01: As tipologias de Meio Ambiente segundo Sauvé (1996). Fonte: Adaptado de Sauvé (1996, p. 13).

\begin{tabular}{|c|c|c|c|}
\hline Meio Ambiente & Tipo de relação & Principais características & $\begin{array}{l}\text { Exemplos de estratégias de } \\
\text { ensino/aprendizagem }\end{array}$ \\
\hline como natureza & $\begin{array}{l}\text { para ser apreciada, respeitada } \\
\text { e preservada }\end{array}$ & $\begin{array}{l}\text { o original, "puro" meio } \\
\text { ambiente; natureza como } \\
\text { uma catedral; natureza como } \\
\text { um útero }\end{array}$ & $\begin{array}{l}\text { * exposições da natureza; } \\
\text { *imersão na natureza }\end{array}$ \\
\hline como um recurso & a ser gerenciado & $\begin{array}{l}\text { nossa herança coletiva } \\
\text { biofísica, sustentação da } \\
\text { qualidade de vida }\end{array}$ & $\begin{array}{l}\text { 3Rs campanhas; auditoria do } \\
\text { consumo de energia }\end{array}$ \\
\hline $\begin{array}{l}\text { como um } \\
\text { problema }\end{array}$ & a ser resolvido & $\begin{array}{l}\text { o meio ambiente biofísico, } \\
\text { defensor da vida, ameaçado } \\
\text { pela poluição, deterioração }\end{array}$ & $\begin{array}{l}\text { * estratégias de resolução de } \\
\text { problemas } \\
\text { * estudo de caso }\end{array}$ \\
\hline $\begin{array}{l}\text { como um lugar } \\
\text { para viver }\end{array}$ & $\begin{array}{l}\text { conhecer e aprender sobre, } \\
\text { planejar para, cuidar de }\end{array}$ & $\begin{array}{l}\text { nosso ambiente de vida diária } \\
\text { com seus componentes } \\
\text { socioculturais, tecnológicos e } \\
\text { históricos }\end{array}$ & $\begin{array}{l}\text { * história ambiental do nosso } \\
\text { lugar } \\
\text { * projeto eco-jardinagem }\end{array}$ \\
\hline como biosfera & $\begin{array}{l}\text { em que todos nós vivemos } \\
\text { juntos para o futuro }\end{array}$ & $\begin{array}{l}\text { a nave espacial terra, objeto } \\
\text { da consciência planetária, um } \\
\text { modo de interdependência } \\
\text { entre os seres e as coisas }\end{array}$ & $\begin{array}{l}\text { * estudo de caso sobre um } \\
\text { problema global; } \\
\text { * contar histórias ilustrando } \\
\text { diferentes cosmologias }\end{array}$ \\
\hline $\begin{array}{l}\text { como um projeto } \\
\text { comunitário }\end{array}$ & em que se envolve & $\begin{array}{l}\text { uma vida compartilhada } \\
\text { milieu; o foco de análise } \\
\text { crítica social, uma } \\
\text { preocupação política da } \\
\text { comunidade }\end{array}$ & $\begin{array}{l}\text { * processo de pesquisa-ação } \\
\text { (participativa integrante } \\
\text { destinado a transformação); } \\
\text { fóruns de questão ambiental }\end{array}$ \\
\hline
\end{tabular}

Para Sauvé (1996), embora cada um destes seis conceitos arquetípicos esteja no centro de uma representação social particular do ambiente, pode-se observar em cada um, uma representação singular. O núcleo conceitual pode ser enriquecido (no centro ou na periferia do sistema de representação) por outro conceito, ou por uma combinação de elementos característicos de dois ou três arquetípicos. Esses seis 
conceitos são eminentemente complementares e podem ser combinados de várias maneiras. Eles podem ser considerados a partir de uma perspectiva síncrona: realmente coexistem e podem ser identificados em diferentes práticas e discursos contemporâneos relativos à educação ambiental. Mas, eles também podem ser abordados diacronicamente, como sendo também o resultado de uma evolução no tempo.

\subsection{CONTEXTUALIZAÇÃO DA PESQUISA}

O Laboratório de Divulgação Científica e Ensino de Ciências (LABDEC) do Centro Federal de Educação Tecnológica Celso Suckow da Fonseca (CEFET/RJ) desenvolveu ao longo de 2016 o Projeto Educatrilhas. Este projeto foi coordenado por pesquisadores professores e estudantes de Graduação e Pós-Graduação Stricto Sensu, objetivando investigar o potencial das trilhas ecológicas para a formação socioambiental dos indivíduos. Neste trabalho, buscou-se estabelecer como as trilhas ecológicas, mediadas a partir da materialização de um planejamento que privilegie a interpretação ambiental e o discurso interdisciplinar, podem subsidiar concepções ambientais de caráter mais robusto, crítico e complexo.

Dentro deste contexto, o presente estudo buscou identificar e analisar as compreensões sobre meio ambiente de vinte estudantes antes e depois de realizarem a trilha denominada "Trilha do Estudante" no Parque Nacional da Tijuca (PARNA Tijuca), Nossas análises se apoiaram nas tipologias de meio ambiente propostas por Sauvè (1996). Na figura 01 é apresentado o PARNA Tijuca, com seus respectivos setores ecológico-paisagísticos. 
Figura 01: Limites do PARNA Tijuca, com seus respectivos setores ecológicos paisa gísticos: Setor A (azul) - Floresta da Tijuca; Setor B (laranja) - Serra da Carioca; Setor C (vermelho) - Pedra da Gávea / Pedra Bonita, Setor D (rosa)- Pretos Forros / Covanca. Fonte: www.rio.ig.com.br (2012)

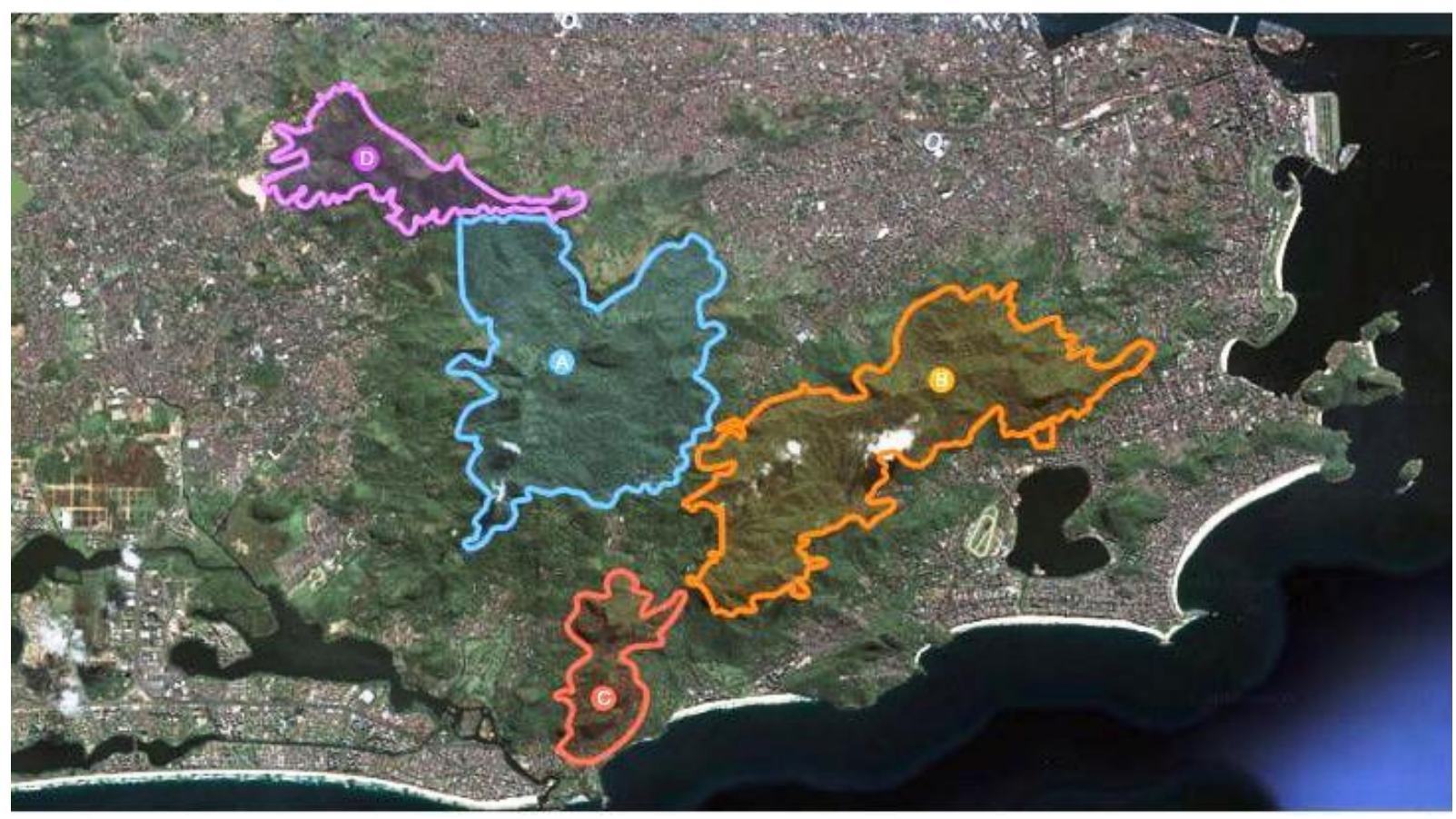

Vale destacar, conforme Siqueira (2013), que o PARNA Tijuca, popularmente conhecido por Floresta da Tijuca, apresenta cerca de 3.900 hectares de área, é uma floresta secundária em estado avançado de regeneração, representando um dos pequenos fragmentos ainda existentes de Mata Atlântica no coração da cidade do Rio de Janeiro.

\section{METODOLOGIA}

Por meio do Projeto Educatrilhas foram mediadas 04 (quatro) visitas guiadas à Trilha do Estudante localizada no setor A do PARNA Tijuca, totalizando 111 (cento e onze) estudantes de instituições de ensino superior públicas e privadas do município do Rio de Janeiro. As trilhas ocorreram em datas e horários diurnos pré-agendados, com no máximo 30 visitantes, divididos em três grupos de 10 estudantes. Cada grupo foi guiado e mediado por três pesquisadores do Projeto Educatrilhas, e, percorriam a Trilha do Estudante, perpassando por 08 (oito) estações interpretativas 
estruturadas previamente. As estações interpretativas são locais, que por seus atributos naturais e paisagísticos, constituem locais privilegiados para abordagens de caráter científico e interdisciplinar. São apresentadas as estações com sucinto resumo de seus potenciais discursivos:

- Ponto de sensibilização - apresentação do grupo e objetivo da pesquisa, explicação do PARNA Tijuca como Unidade de Conservação (UC), abordagem sobre aspectos comportamentais e éticos durante a visitação, momento de relaxamento, e realização das entrevistas pré-trilha;

- Ponto inicial da trilha - apresentação da Trilha dos Estudantes, e abordagem sobre a influência antrópica em trilhas (pisoteio; alteração na composição estrutural; diversidade florística; e perturbação sensorial);

- Estação da Serrapilheira - momento dialógico sobre as funções da floresta, de sua fauna e sua flora;

- Cascatinha Taunay - abordagem sobre aspectos históricos, artísticos, geográficos, e socioeconômicos;

- Caminho das dracenas - discussão sobre espécies invasoras e exóticas;

- Ponto CEDAE - discussão sobre assoreamento, lixiviação e eutrofização;

- Estação da Palmeira Imperial - discussão sobre plantas epífitas e parasitas;

- Museu dos Visitantes - visita ao museu do PARNA Tijuca e realização das entrevistas pós-trilha.

Vale destacar que para cada visita era formado aleatoriamente um subgrupo de cinco estudantes para serem entrevistados, antes e após percorrer o trajeto da trilha. As entrevistas, gravadas em áudio e transcritas na íntegra, ocorriam no próprio PARNA Tijuca com o objetivo de levantar as percepções de meio ambiente dos entrevistados. Nas figuras 2 e 3 são apresentadas fotografias de atividades desenvolvidas pelo Projeto Educatrilhas durante a execução da trilha. 
Figura 02: Parada dialogada em ponto histórico da trilha. Fonte: Autores.

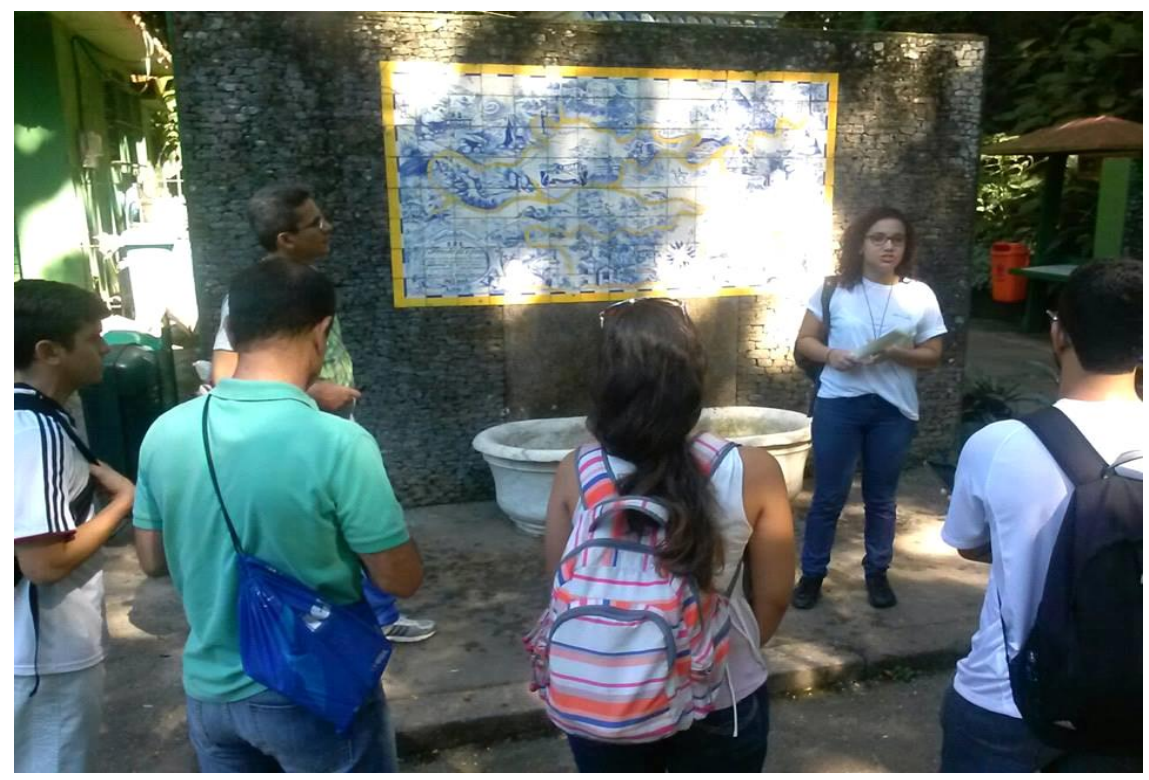

Figura 03: Estudantes em momento de observação da vegetação nativa e exótica. Fonte: Autores.

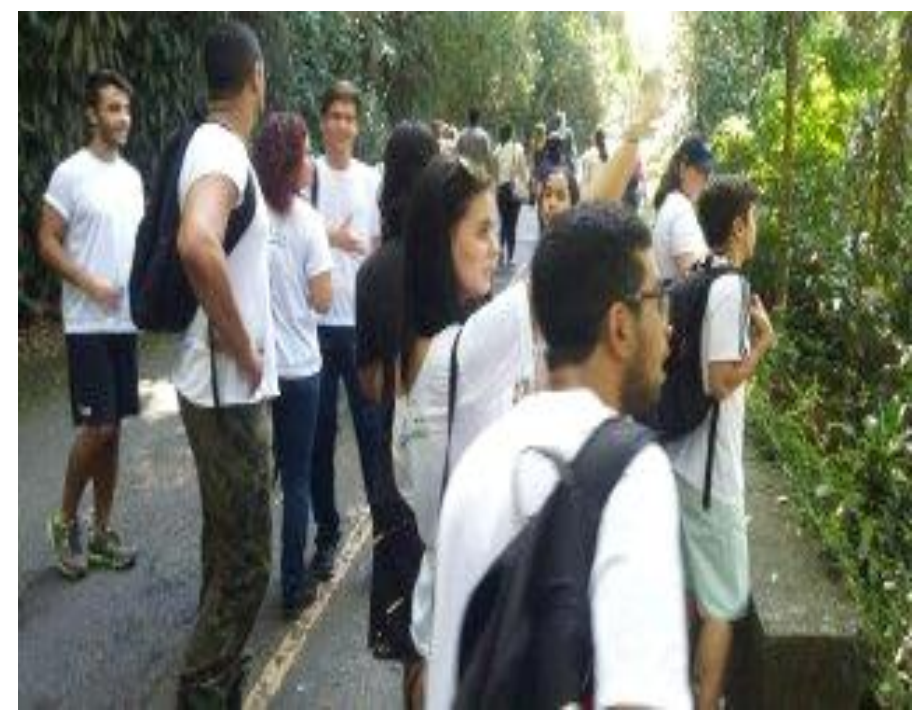

Além das perguntas que contribuem para traçarmos um perfil dos entrevistados, como idade, curso, período e onde residem, foi perguntado aos estudantes antes e depois da trilha:

- O que você entende por meio ambiente?

- Como é a sua relação com o meio ambiente? 
- Você considera que as suas atitudes geram consequências para o meio ambiente?

As entrevistas constituem os dados de análise para um estudo qualitativo sob um comparativo do impacto da realização da trilha, na mudança, ou não, de percepções e compreensões, a respeito do entendimento conceitual sobre meio ambiente. Pois, como salientam Denzin e Lincoln (2006), um estudo de natureza qualitativa é uma atividade situada que localiza o observador no mundo. O caráter qualitativo corporifica uma abordagem naturalista, interpretativa, para o mundo, o que significa que seus pesquisadores estudam as coisas em seus cenários naturalísticos, tentando significar, ou interpretar, os fenômenos em termos dos entendimentos que as pessoas e eles conferem.

Cabe enfatizar que a análise qualitativa de um texto é sujeita a diferentes percepções; pesquisadores diferentes podem ter olhares e insights diferenciados ao analisarem um mesmo material. Assim, ao longo da análise dos dados, foram utilizadas transcrições na integra das falas dos participantes como subsídios para as interpretações feitas no estudo.

Para fundamentar nossas análises apoiamo-nos na Analise de Contéudo (AC), que segundo Bardin (2006) constitui-se como um conjunto de técnicas de análise com o objetivo de obter indicadores que permitam fazer inferências às condições de produção/recepção das mensagens emitidas. A AC tem como etapas fundamentais: categorização, descrição e interpretação dos dados. A categorização deve ser realizada pautada em categorias a priori, que surgem a partir do referencial teórico, e com categorias a posteriori, elaboradas durante e após a análise do material. Ressalta-se que a definição das categorias é estabelecida a critério dos pesquisadores e, por isso, podem ser assumidas diversas possibilidades de categorização, dependendo da interpretação do pesquisador. 
A presente pesquisa atente as exigências do Comitê de Ética segundo parecer emitido sob o número 565/10.

\section{Resultados e Discussão (Estilo “CABeçalho 1")}

Dos vinte entrevistados, havia onze mulheres e nove homens, todos com faixa etária entre 20 e 30 anos. O Curso Superior em Gestão Ambiental predominou na amostra, sendo representado por 14 estudantes e os demais cursavam Ciências Biológicas. Quanto ao local em que residem, 14 pertencem a Zona Norte do Rio de Janeiro, 4 a Zona Oeste e 2 a Zona Sul.

Após estabelecermos esse perfil do grupo investigado, apresentamos no gráfico abaixo o resultado referente à questão: O que você entende por meio ambiente? Vale destacar que o estabelecimento destas categorias de respostas foi apoiado na Análise de Conteúdo (BARDIN, 2006).

Gráfico 01: Compreensões antes e após a realização da Trilha dos Estudantes, referente à primeira questão. Fonte: Autores, 2016.

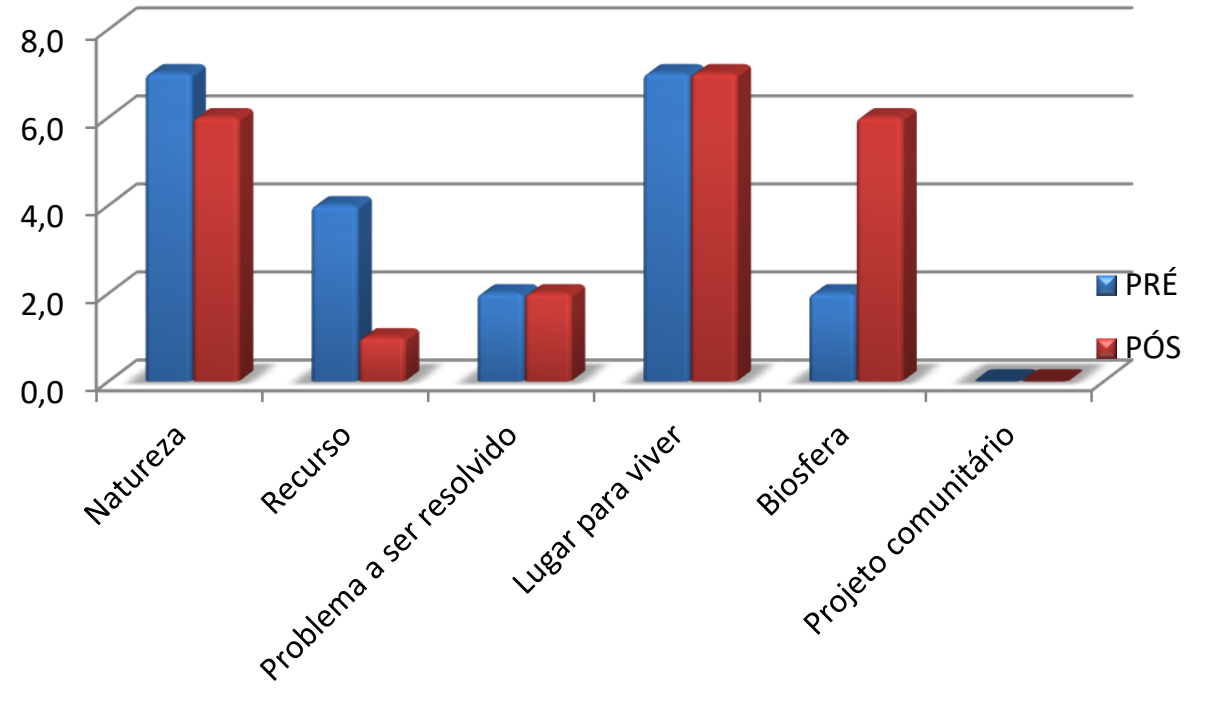


No gráfico acima se destacam as compreensões, com maior ocorrência, que remetem a definição de meio ambiente sob a égide de três tipologias: como natureza, como lugar para viver, como uma biosfera. De acordo com Sauvé (1996) o indivíduo ao entender meio ambiente como natureza, o concebe como um ambiente original, "puro", que deve ser apreciado, respeitado, protegido e observado, um espaço de que os seres humanos têm dissociado e para qual devem aprender a se relacionar como ser. Podemos constatar essa tipologia na fala do aluno P2 antes de realizar a trilha: "Ah, meio ambiente é um lugar lindo, quando a gente vem e vê as águas caindo da cachoeira a gente fica calma, se distrai um pouco."

Pinheiro et al (2016) em estudo similar também observaram que uma parte significativa dos estudantes percebem meio ambiente como espaço restrito flora e fauna, sem qualquer relação entre o homem e o meio. Para Reigota (2010) essa percepção reducionista traz em seu bojo uma visão naturalizada de meio ambiente, relacionando-o apenas aos elementos naturais.

Após a realização da Trilha do Estudante foi possível observar que houve um decréscimo no entendimento de meio ambiente dessa concepção naturalística. Essa constatação nos traz à crítica de que compreender o meio ambiente como espaços de inter-relações em que o homem também esteja inserido e peremptoriamente ativo, aproxima-se de outras tipologias, que não uma concepção naturalística.

Ainda em relação à primeira questão nota-se um aumento, após a mediação, nas compreensões de meio ambiente entendido como biosfera. Para Sauvé (1996), meio ambiente como biosfera é um mundo de interdependência entre os seres e as coisas, apelando para a solidariedade entre todos os povos. A fala do estudante P18, após a realização da trilha, corrobora como esse entendimento: "Anh, meio ambiente seriam as relações do biológico com o não biológico, como, o biótico e o abiótico, e essas relações têm dois tipos né, as que a gente vê na cidade e as que a 
gente vê num ambiente de floresta. Nas cidades a gente vê um ambiente muito degradado onde as pessoas não têm noção de consciência ambiental, há mais incidência de ruídos, mais poluição. Já a floresta é m outro tipo de ambiente, onde você tem a presença de vida animal e vegetal uma relação mais estável, mais estabilizada, completamente diferente do que você vê na cidade. Precisamos entender que uma coisa está relacionada a outra: sem os espaços verdes a vida na cidade diminui de qualidade."

Compreender meio ambiente no sentido de biosfera corrobora com Jacobi (2003), para quem meio ambiente configura-se como um importante espaço sociopolítico de coletividade e correlacional, perpassando discussões sobre igualdade, solidariedade e qualidade de vida. Essa compreensão traz uma visão sociopolítica aonde os impactos no ambiente afetam outros com subjetividades muitas vezes antagônicas.

No gráfico 2 apresentamos os resultados das entrevistas sobre a questão: Como é a sua relação com o meio ambiente?

Gráfico 02: Compreensões antes e após da realização da Trilha dos Estudantes referente à segunda questão. Fonte: Elaborado pelos autores, 2016.

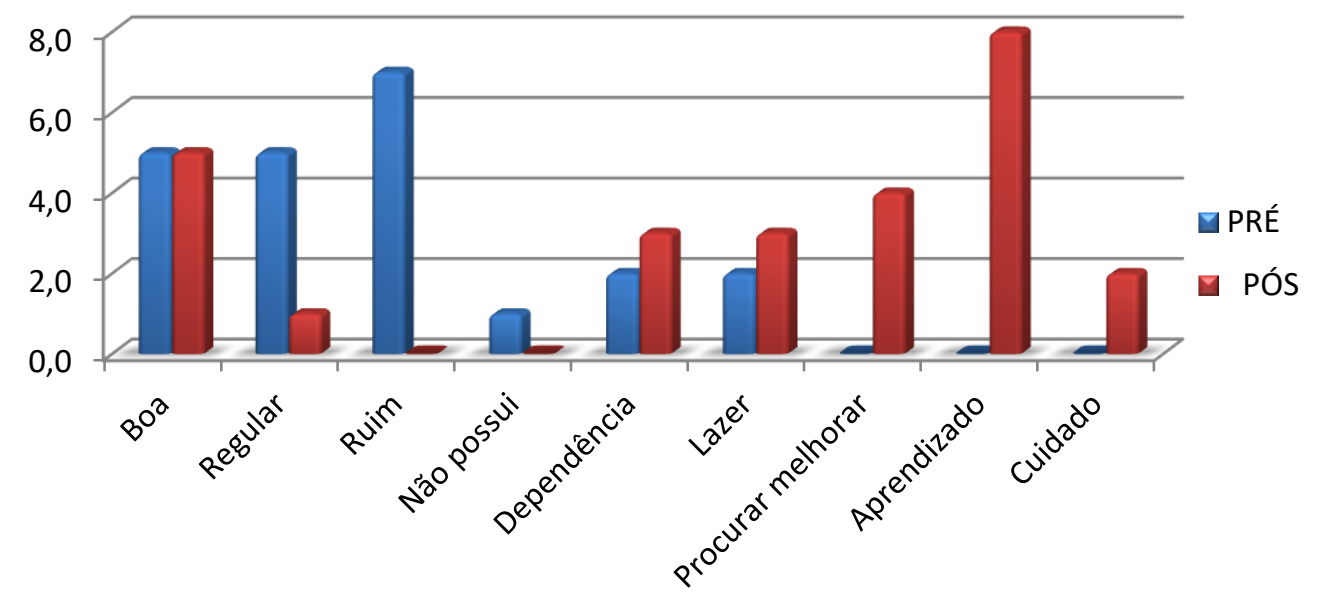


Ao analisarmos os dados destacamos que após a realização da Trilha do Estudante, não ocorreram respostas que coloquem a relação do entrevistado com o meio ambiente, como uma relação "ruim" ou que inexiste ("não possui"). Isso nos permite dizer que, quanto a não expressão da relação "ruim", remete a interpretação de que os estudantes, após a realização da trilha, se percebem como agentes que de alguma maneira interagem positivamente (seja como proteção ou mitigação) com o meio ambiente. A não ocorrência de falas, após a trilha, em que os estudantes se entendem como que "não possuem" relação com o meio ambiente, nos faz destacar um ponto muito importante: àqueles que antes se entendiam alheios (à parte, amorfos, inócuos) ao meio ambiente, passam então a se colocar como agentes que de alguma maneira se relacionam (interagem, fazem parte, impactam) no ambiente. A fala do aluno P10 após a realização da trilha externalizam essas compreensões.

Aluno P10" "A minha relação com a natureza a partir de hoje foi assim bem próxima, eu aprendi coisas novas sobre a natureza e fiquei um pouco mais ligado o que ocorre na natureza no nosso dia a dia."

Ainda nessa questão podemos destacar a presença de duas percepções, após a realização da trilha, que à priori não foram expostas. São elas: "aprendizado" e "cuidado". Sob os auspícios de Sauvé (1996), essas percepções nos permitem dizer que, em mais da metade das entrevistas feitas após a trilha, aparecem indicações que seguem para uma tomada de consciência, no sentido de que as ações humanas causam algum tipo de impacto no ambiente. Podem ser impactos que de alguma forma colaboram para a saúde e vitalidade desse ambiente, ou, que de alguma maneira trabalha de forma contrária. A fala do entrevistado P11 exemplifica a situação discutida: "Ah, eu vou procurar tá mais envolvida, fazer talvez mais trilhas, 
tentar cuidar mais do ambiente a minha volta, que a gente vê assim, a gente sente aqui como o clima é diferente né! O ar é diferente por causa dessa natureza."

Quando questionados sobre as consequencias de suas atitudes para o meio ambiente, observamos que:

Gráfico 03: Resultados das entrevistas antes e após a realização da Trilha dos Estudantes, quanto a questão: Você considera que as suas atitudes geram consequências para o meio ambiente? Fonte: Elaborado pelos autores, 2016.

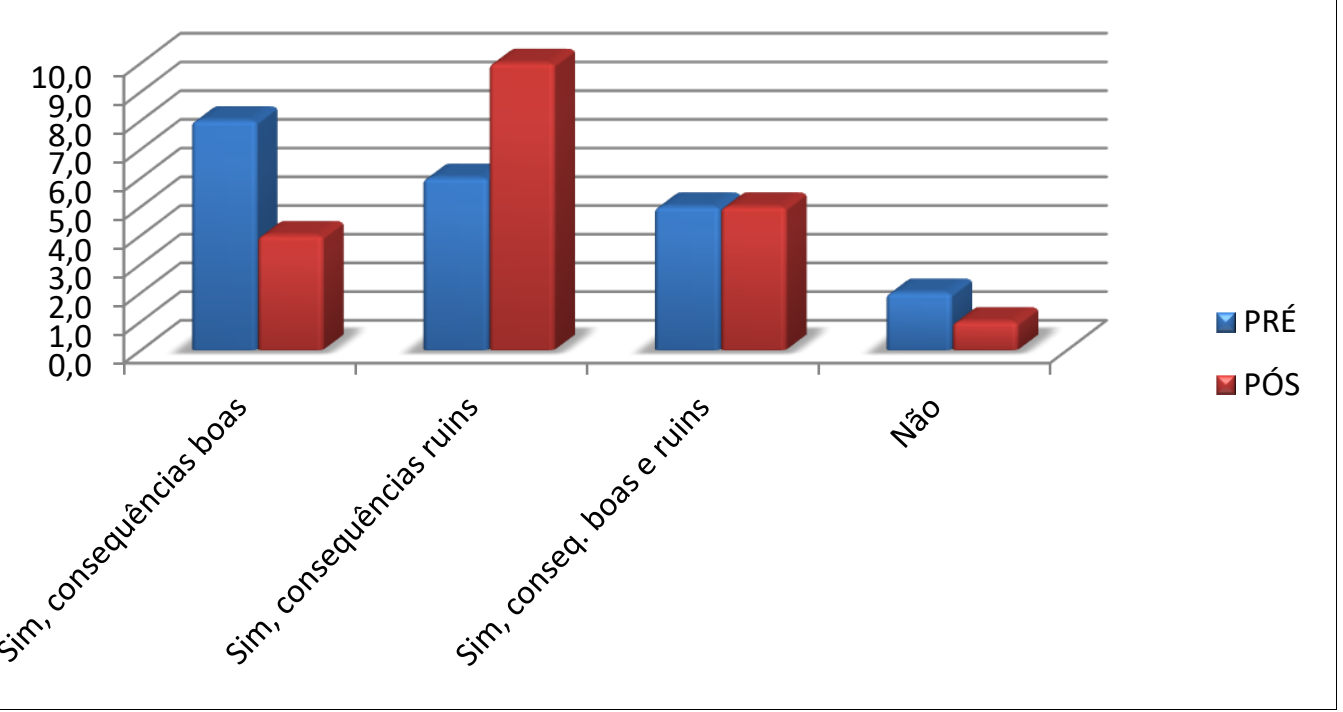

Nota-se que houve a diminuição das situações em que o indivíduo afirma que suas atitudes geram consequências boas para a natureza, e um acréscimo de opiniões que consideram que as suas atitudes geram consequências ruins para a natureza. Tais alterações remetem-nos apontar que a mediação dialógica realizada ao longo da Trilha do Estudante, levou os entrevistados a colocarem-se como agentes impactantes do ambiente. As falas dos alunos P9 e P15 coadunam essa compreensão, respectivamente. 
Aluno P9:"Sim, e depois da trilha a gente percebe que muitas coisas que a gente faz realmente afeta e, de formas que a gente nem imagina, são muito grandes."

Aluno P15 "Sim gera, não só os grandes impactos do governo e indústrias, que as pessoas sempre falam, mas cada cidadão contribui para a degradação da natureza."

Podemos relacionar esses entendimentos com Teramussi (2008), ao salientar que os ambientes (físico, social, imaginário e psicológico) que cercam os indivíduos e grupos sociais, têm a capacidade de influenciar suas percepções e atitudes. A autora ainda destaca que a percepção do ambiente é, de forma geral, resposta dos sentidos aos estímulos externos; o que é visto guarda relação com o contexto sociocultural do indivíduo e a partir dessa rede de associações passa atribuir valores, positivos ou negativos.

Costa et al. (2014) defendem que a utilização das áreas verdes, como espaço educativo, aliado ao desenvolvimento de atividades diversificadas, seja um caminho viável para elucidar as possíveis dificuldades inerentes ao ensino e aprendizagem de conteúdos ecológicos no ensino de Ciências. Dentro desse contexto, as trilhas ecológicas tornam-se "laboratórios vivos", ao permitir o desenvolvimento de ações educativas eficazes quanto à aprendizagem de conceitos ecológicos, por aliarem teoria e prática através da interpretação e análise dos recursos naturais "in loco" por meio da reflexão sobre as relações entre o ser humano e o meio ambiente.

Para Costa et al. (op. cit.) as trilhas ecológicas têm como finalidade incentivar a captação e compreensão dos conceitos básicos da ciência em um nível crescente de complexidade; como também desenvolver nos estudantes a capacidade de observação, interpretação e reflexão crítica dos recursos naturais, bem como a promoção da sensibilização ambiental com relação à importância das áreas verdes 
para a regulação do equilíbrio ambiental que afeta diretamente o homem, os demais seres vivos e os diversos sistemas biogeoquímicos do planeta.

Nesse sentido, corroborando com Sauvé (1996), as trilhas ecológicas podem levantar questões e discussões ambientais sob várias proposições e conjecturas, impactando fortemente as compreensões iniciais daqueles que as percorrem. Essa dinâmica, como salienta a autora, impõe ao educador-mediador uma busca constante de aporte acadêmico que o direcione em seus trabalhos, pois exige uma práxis holística e complexificadora, não aceitando uma base epistêmica rígida e intransigente. Sensibilizar o indivíduo estimulando-o a percepções diferenciadas de meio ambiente oferece subsídios para uma construção autônoma e significativa de conceitos que se refletirão em comportamentos individuais e coletivos, de caráter contributivo, favorável e mitigatório para o ambiente. Discutir sobre meio ambiente é interessar-se pela vida, tomando "vida" num conceito superlativado que abarque fenômenos (relacionais e interacionais) sob aspectos (biológicos, químicos, físicos e antrópicos) que influenciam em sua existência, persistência e qualidade. Como salienta a autora, essa discussão é assunto urgente e indispensável que deve ser abordado em todos os níveis e espaços de ensino-aprendizagem.

\section{CONSIDERAÇÕES FINAIS}

Diante dos resultados obtidos nesta pesquisa, infere-se que as trilhas ecológicas podem ser tomadas como espaços educativos não formais institucionalizados, bastante significativos para estudos de percepção e educação ambiental. A operacionalização de práticas pedagógicas, em especial, aquelas cognoscitivas com basilar interdisciplinar nesses espaços corroboram com Teramussi (2008), para quem as relações que determinados grupos estabelecem com o meio ambiente, intricam ordens cognitivas, afetivas e éticas. A forma como sentem, 
pensam e agem determinados grupos, no âmbito da paisagem vivida, pode-se se dar no campo da percepção e interpretação do ambiente.

As trilhas, como espaços naturais abertos que são, criam ambientes propícios para estimular e sensibilizar os sentidos humanos, favorecendo o desenvolvimento de uma gama de práticas e abordagens interpretativas. Nesse sentido, as trilhas constituem ambientes para uma práxis educativa dialógica legitimando um processo de integração dos estudantes com o mundo a sua volta de forma mais crítica e politizada. Conforme constatado nas compreensões dos estudantes após a realização da Trilha do Estudante, esses espaços naturais, na perspectiva da educação e interpretação ambiental, constituem espaços educativos com possibilidade alcance a novos patamares no entendimento sobre meio ambiente.

Castoldi et al. (2009) dialogam com esse entendimento, pois salientam que as práticas educativas articuladas a educação ambiental devem desenvolver nos estudantes mudanças de comportamento pessoal, de atitudes e de valores de cidadania, a fim de que sejam propiciadas novas relações entre o homem e o meio ambiente.

Nesse sentido, a pesquisa desenvolvida pelo Projeto Educatrilhas vem como contributo para a área de Ensino, pois estimula um repensar epistêmico sobre as possibilidades pedagógicas das trilhas ecológicas e as abordagens que nelas podem ser desenvolvidas, catalisando discussões e apropriações sobre meio ambiente da perspectiva crítica e correlacional.

\section{AGRADECIMENTOS}

Os autores agradecem a CAPES e ao Programa Institucional de Bolsas de Iniciação Científica (PIBIC) do CEFET/RJ pelo suporte dado ao trabalho. 


\section{REFERÊNCIAS}

BARDIN, L. Análise de Conteúdo. Lisboa: Edições 70, 2006.

COSTA, E. S. A. et al. Trilhas interpretativas na área verde da escola como estratégia de ensino para aprendizagem de conceitos ecológicos. Revista da SBEnBio, no 07, p. 1820-1831, out. 2014.

CASTOLDI, R. et al. Percepções dos problemas ambientais por alunos do ensino médio. Revista Brasileira de Ciência, Tecnologia e Sociedade, v.1, n.1, p. 56-80, 2009.

DENZIN, N. K.; LINCOLN, Y. S. Introdução: a disciplina e a prática da pesquisa qualitativa. In . (Org.) DENZIN, N. K.; LINCOLN, Y. S. Planejamento da pesquisa qualitativa: teorias e abordagens. Porto Alegre: Artmed, 2006, p. 15-42.

FAGGIONATO S. Percepção ambiental. Programa Educ@r. Disponível em: http://educar.sc.usp.br/biologia/textos/ m_a_txt4.html. Acesso em: 21 mar. 2014.

GONÇALVES, M. Educação Ambiental: planejamento e uso de trilhas ecológicas interpretativas para estudantes com deficiência intelectual. 2009. 69f. Dissertação (Mestrado em Planejamento e Gestão Ambiental) Universidade Católica de Brasília. Brasília, 2009.

JACOBI, C. M.; FLEURY, L. C.; ROCHA, A. C. C. L. Percepção ambiental em unidades de conservação: experiência com diferentes grupos etários no parque estadual da serra do rola moça, MG. In: VII Encontro de Extensão da Universidade Federal de Minas Gerais. Anais .... VII Encontro de Extensão da Universidade Federal de Minas Gerais. Belo Horizonte, 2004. p.1-7.

JACOBI, P. R. Educação ambiental, cidadania e sustentabilidade. Cadernos de Pesquisa, n. 118, março/ 2003. 
MARQUES, D. V. Uma proposta de educação ambiental para áreas verdes: o exemplo do bosque John Kennedy, Araguari, MG. In: V Congresso de Ciências Humanas, Letras e Artes. Anais... V Congresso de Ciências Humanas, Letras e Artes. Ouro Preto, 28 a 31 ago. 2001.

MITRAUD, S. (Org.). Manual de ecoturismo de base comunitária: ferramentas para um planejamento responsável. Brasília: WWF Brasil, 2003. 470p.

OLIVEIRA, S. C. C.; NISHIDA, A. K. A interpretação ambiental como instrumento de diversificação das atividades recreativas e educativas das trilhas do Jardim Botânico Benjamim Maranhão (João Pessoa, Paraíba, Brasil). Revista Turismo Visão e Ação Eletrônica, v. 13, n. 2, p. 166-185, 2011.

PARREIRA, L. A.; JOSÉ FILHO, M. A educação não formal: desafios de uma prática pedagógica. Serviço Social \& Realidade, v. 19, n. 1, p. 241-268, 2010.

PINHEIRO, L. B. C.; LIMA, F. de S.; ROCHA, T. T.; MARTINS, A. C. Ressignificação das percepções de natureza, meio ambiente e educação ambiental através de uma trilha ecológica. Revista Brasileira de Educação Ambiental, v.11, n.1, p. 196-214, 2016.

REIGOTA, M. A Educação Ambiental frente aos desafios apresentados pelos discursos contemporâneos sobre a natureza. Educação e Pesquisa, v.36, n.2, p. 539-553, 2010.

SAUVÈ, L., Environmental Educationand Sustainable Development: A Further Appraisal. Canadian Journal of Environmental Education, 1, Spring 1996. Universityof Quebec, Montreal, Canada.

SIQUeIRA, A. E. de (Org.). Guia de campo do Parque Nacional da Tijuca. Rio de Janeiro: UERJ/IBRAG, 2013.

TERAMUSSI, T. M. Percepção ambiental de estudantes sobre o Parque Ecológico do Tietê, São Paulo - SP. 105f. Dissertação de Mestrado apresentada ao Programa de 
Pós-Graduação em Ciência Ambiental da Universidade de São Paulo. São Paulo, 2008.

TRILLA, J. A educação não formal. In: ARANTES; Valéria Amorim (Org.). Educação formal e não formal. São Paulo: Summus, 2008.

VASCONCELLOS, J. M. de O. Avaliação da visitação pública e da eficiência de diferentes tipos de trilhas interpretativas no Parque Estadual Pico do Murumbi e Reserva Natural Salto Morato - PR. 139f. Tese (Doutorado em Ciências Florestais). Pós- Graduação em Engenharia Florestal, Universidade Federal do Paraná. Curitiba, 1998.

Recebido em: Março de 2017. Publicado em: Agosto de 2017. 